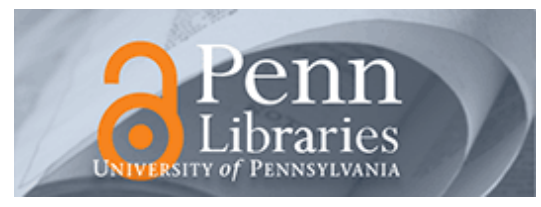

University of Pennsylvania

ScholarlyCommons

Business Economics and Public Policy Papers

Wharton Faculty Research

4-23-2009

\title{
Changes in the Incidence and Duration of Periods Without Insurance
}

David M. Cutler

Alexander M. Gelber

University of Pennsylvania

Follow this and additional works at: https://repository.upenn.edu/bepp_papers

Part of the Economics Commons, and the Public Affairs, Public Policy and Public Administration Commons

Recommended Citation

Cutler, D. M., \& Gelber, A. M. (2009). Changes in the Incidence and Duration of Periods Without Insurance. The New England Journal of Medicine, 360 (17), 1740-1748. http://dx.doi.org/10.1056/NEJMsa0804668

This paper is posted at ScholarlyCommons. https://repository.upenn.edu/bepp_papers/143

For more information, please contact repository@pobox.upenn.edu. 


\section{Changes in the Incidence and Duration of Periods Without Insurance}

\section{Abstract \\ BACKGROUND}

Policymakers have recently proposed ways of providing health care coverage for an increased number of uninsured persons. However, there are few data that show how the incidence and duration of periods in which persons do not have insurance have changed over time.

\section{METHODS}

We used two data sets from the Survey of Income and Program Participation of the U.S. Census Bureau: one that covered the period from 1983 through 1986 (25,946 persons), and another that covered the period from 2001 through 2004 (40,282 persons). For each set of years, we estimated the probability that a person would be uninsured for some period of time and the probability that a person would subsequently obtain private or public insurance. We also estimated the probabilities that persons in various demographic groups would become uninsured over the course of a year and would remain uninsured for various amounts of time.

\section{RESULTS}

The percentage of the population that lost insurance in a 12-month period increased from $19.8 \%$ in 1983-1986 to $21.8 \%$ in $2001-2004(P=0.04)$. The percentage that was uninsured for a period of time increased markedly among persons with the lowest educational level and predominantly represented loss of private coverage. The percentage of new uninsured periods that ended within 24 months increased from $73.8 \%$ to $79.7 \%$ between the two study periods $(P<0.001)$; increases were seen in all age groups and among persons of all educational levels. Transition from no insurance to private insurance decreased from $65.2 \%$ to $59.2 \%(P<0.001)$. Transition from no insurance to public insurance increased from $8.7 \%$ to $20.4 \%(P<0.001)$.

\section{CONCLUSIONS}

As compared with the years from 1983 through 1986, from 2001 through 2004, more people, particularly those with the lowest educational level, had periods in which they were not insured. The periods without insurance were shorter in 2001-2004 than they were in 1983-1986, since an increase in transitions to public coverage offset a reduction in transitions to private coverage. Our results portend difficulties if private coverage continues to decline and is not offset by further expansions of public insurance.

\section{Disciplines}

Economics | Public Affairs, Public Policy and Public Administration 


\title{
Changes in the Incidence and Duration of Periods without Insurance
}

\author{
David M. Cutler, Ph.D., and Alexander M. Gelber, Ph.D.
}

\begin{abstract}
From the Department of Economics, Harvard University, and the National Bureau of Economic Research - both in Cambridge, MA. Address reprint requests to Dr. Cutler at the Department of Economics, Harvard University, 1875 Cambridge St., Cambridge, MA 02138, or at dcutler@ harvard.edu.
\end{abstract}

N Engl J Med 2009;360:1740-8. Copyright (c) 2009 Massachusetts Medical Society.

\section{ABSTRACT}

\section{BACKGROUND}

Policymakers have recently proposed ways of providing health care coverage for an increased number of uninsured persons. However, there are few data that show how the incidence and duration of periods in which persons do not have insurance have changed over time.

\section{METHODS}

We used two data sets from the Survey of Income and Program Participation of the U.S. Census Bureau: one that covered the period from 1983 through 1986 (25,946 persons), and another that covered the period from 2001 through 2004 (40,282 persons). For each set of years, we estimated the probability that a person would be uninsured for some period of time and the probability that a person would subsequently obtain private or public insurance. We also estimated the probabilities that persons in various demographic groups would become uninsured over the course of a year and would remain uninsured for various amounts of time.

\section{RESULTS}

The percentage of the population that lost insurance in a 12-month period increased from $19.8 \%$ in $1983-1986$ to $21.8 \%$ in $2001-2004$ ( $\mathrm{P}=0.04$ ). The percentage that was uninsured for a period of time increased markedly among persons with the lowest educational level and predominantly represented loss of private coverage. The percentage of new uninsured periods that ended within 24 months increased from $73.8 \%$ to $79.7 \%$ between the two study periods $(\mathrm{P}<0.001)$; increases were seen in all age groups and among persons of all educational levels. Transition from no insurance to private insurance decreased from $65.2 \%$ to $59.2 \%$ ( $\mathrm{P}<0.001)$. Transition from no insurance to public insurance increased from $8.7 \%$ to $20.4 \%(\mathrm{P}<0.001)$.

\section{CONCLUSIONS}

As compared with the years from 1983 through 1986, from 2001 through 2004, more people, particularly those with the lowest educational level, had periods in which they were not insured. The periods without insurance were shorter in 2001-2004 than they were in 1983-1986, since an increase in transitions to public coverage offset a reduction in transitions to private coverage. Our results portend difficulties if private coverage continues to decline and is not offset by further expansions of public insurance. 
T HE NUMBER OF AMERICANS WHO DO NOT have health insurance for an entire year has increased markedly in recent years, from 32 million (15\% of the nonelderly population) in 1988 to 45 million (17\% of the nonelderly population) in 2007. ${ }^{1}$ Lack of insurance for an entire year reflects only one dimension of insurance coverage, however. Data from the 1980s suggested that about twice as many people were uninsured at some point in a year than were uninsured for the entire year. ${ }^{2}$

Being uninsured (i.e., having what we term an uninsured period), even temporarily, is harmful to a person's health. ${ }^{3,4}$ Uninsured periods of longer duration have a larger adverse effect on health than periods of shorter duration ${ }^{5-7}$ and may also be concentrated in a group that is initially less healthy. ${ }^{3}$ The status of the uninsured has become particularly important as policymakers consider incremental expansions of health coverage, such as enhanced access to coverage through the Consolidated Omnibus Budget Reconciliation Act (COBRA), which currently ensures coverage for only 18 months. ${ }^{8}$

Over the past several decades, economic and social factors have contributed to both longer and shorter durations of uninsured periods. The increase in temporary and contingent work, ${ }^{9}$ along with increased cost-sharing for insurance, ${ }^{10}$ may lead to more long-term uninsured periods. On the other hand, eligibility for public insurance has been expanded to include not only single women and children in low-income families but also dual-parent families and families at higher income levels, a change that should lead to shorter uninsured periods. The net change over time in the incidence and duration of periods without insurance is therefore uncertain.

Data from the National Survey of America's Families (NSAF) show that there were relatively small changes in the distribution of insurance coverage between 1998-1999 and 2001-2002, with a slight trend toward shorter uninsured periods among children ${ }^{11}$; however, the period of time covered by that study ( 3 years) is limited. Data from the Survey of Income and Program Participation (SIPP) of the U.S. Census Bureau in the mid-to-late 1980s and early 1990s show that median durations of uninsured periods were in the range of 4 to 8 months, with no discernible trend over time. ${ }^{12-15}$ However, these analyses have not been updated with the use of more recent SIPP data. Research on the loss of insurance has not tracked its evolution over time, nor has a hazard model for losing insurance been estimated. ${ }^{16}$

We examined changes over time in the incidence and duration of periods without insurance, using data from 1983 through 1986 and 2001 through 2004. The overall economy was better in 2001-2004 than in 1983-1986, but in each case it was in recovery from a recession. We estimated hazard models for both gaining and losing insurance, controlling for employment changes in order to minimize the effect of economic factors, and examined population groups separately according to age and educational level. Finally, we evaluated transitions to and from public and private insurance in the two survey periods.

METHODS

\section{DATA SET}

We used data from the SIPP, a longitudinal, stratified, random sample of families in the United States. ${ }^{17}$ All participants provided informed consent. The SIPP full panel that began in the fall of 1983 (the 1983-1986 SIPP) enrolled persons from October 1983 through January 1984 and followed them for 32 months, whereas the SIPP full panel that began in 2001 (the 2001-2004 SIPP) enrolled persons from October 2000 through January 2001 and followed them for 36 months. We addressed this difference in panel lengths by estimating a hazard model for the duration of uninsured periods. To make length-of-time windows equal for the two survey periods, when we analyzed data on whether the person was uninsured at all, we used data from only the first 32 months of the 20012004 SIPP panel. The use of panels of data covering at least 32 months allowed an analysis of longer periods than those that could be analyzed with the use of the Current Population Survey or the NSAF. Survey participants were asked about a number of socioeconomic variables, including age, race or ethnic group, sex, geographic location, education, work income, number of hours worked per week, capital income, net wealth, and participation in government programs, such as Medicare, Medicaid, and the State Children's Health Insurance Program (SCHIP). Every 4 months (the period of time that was termed a wave), respondents were asked to report whether each member of the family had had health insurance in each of the previous 4 months and, if so, what type of 
health insurance. In the third wave of the survey (12 months from the beginning of the survey period), persons 15 years of age or older reported their health status on a five-point scale in which the possible responses were excellent, very good, good, fair, and poor.

We used the educational level of the family's highest earner as the main socioeconomic variable of interest. We did not use income to categorize families, since a person's cash income may decline with increased health benefits, ${ }^{18,19}$ and educational level is a better proxy for long-term earnings. ${ }^{20,21}$

Our sample was restricted to persons who were 61 years of age or younger at the time of the first survey for each of the 1983-1986 and 2001-2004 panels. The age restriction ensured that no one would become old enough during the survey period to be eligible for Medicare. We also excluded persons who were removed from the sample when the 1983-1986 panel was reduced owing to budget cutbacks and persons who were in the military or who were receiving veterans' payments, as well as their relatives, since they are covered by TRICARE (formerly known as the Civilian Health and Medical Program of the Uniformed Services [CHAMPUS]) or the Civilian Health and Medical Program of the Department of Veterans Affairs (CHAMPVA). These exclusions resulted in a final sample of 25,946 people in the 1983-1986 panel and 40,282 people in the 2001-2004 panel. The sample of persons with an uninsured period comprised 8706 persons in the 1983-1986 panel and 14,443 persons in the 2001-2004 panel who reported being uninsured for some period of time (and who met the other criteria listed above).

\section{STATISTICAL ANALYSIS}

We used a Cox proportional-hazards model to estimate the probability of becoming uninsured in 1983-1986 and 2001-2004, using as covariates a person's age at the time of the first survey $(<18$ years or 18 to 61 years), the educational level of the highest earner (no high-school or General Educational Development [GED] diploma, highschool or GED diploma, some college, or college degree or more), sex, race or ethnic group (white, black, or other), and initial source of coverage (public or private). For every uninsured period in the 1983-1986 and 2001-2004 SIPP surveys, we estimated a competing-risk model for obtaining public or private coverage. The dependent variable was one of three insurance groups: publicly insured, privately insured, or uninsured. We used Lunn and McNeil's Method $\mathrm{B}^{22}$ so that the probability of obtaining private or public health insurance in each month after the onset of an uninsured period (i.e., the baseline hazard) was left unrestricted. In all hazard models, we used a nonparametric baseline hazard, effectively allowing the baseline hazard to vary by month. ${ }^{23}$

After estimating the models for all ages, we reestimated the models with the inclusion of a dummy variable for self-reported fair or poor health status. Because health status was not assessed for persons younger than 15 years of age, these models were for adults only and included data only after the third interview wave (when health status was assessed).

The hazard models and summary statistics were weighted with the use of longitudinal panel weights. Standard errors were adjusted for the complex survey design and for repeated measures, with the use of Stata software, version 9.2.24 We calculated the probability of losing coverage during the course of a year and of obtaining insurance of each type (public or private) in each month for each demographic group in each of our two survey periods. To examine population-constant trends in insurance coverage, we weighted the probabilities for all the results that were specific for age, race or ethnic group, and educational level according to the average of the population distribution of demographic characteristics in the 1983-1986 data and the 2001-2004 data.

\section{RESULTS}

\section{STUDY SAMPLE}

Characteristics of the study sample are shown in Table 1 . The population comprised more adults and racial minorities in 2001-2004 than in 19831986. The average educational level of the primary earner increased over time. The percentage of the population that was uninsured in any month was slightly higher in 2001-2004 than in 1983-1986, though not significantly so $(15.9 \%$ and $15.8 \%$, respectively; $\mathrm{P}=0.07)$. More persons in the 20012004 panel had an uninsured period than did those in the $1983-1986$ panel (37.3\% vs. $35.4 \%, \mathrm{P}<0.001)$.

Hazard-model estimates of the probability of losing coverage and of regaining coverage after 


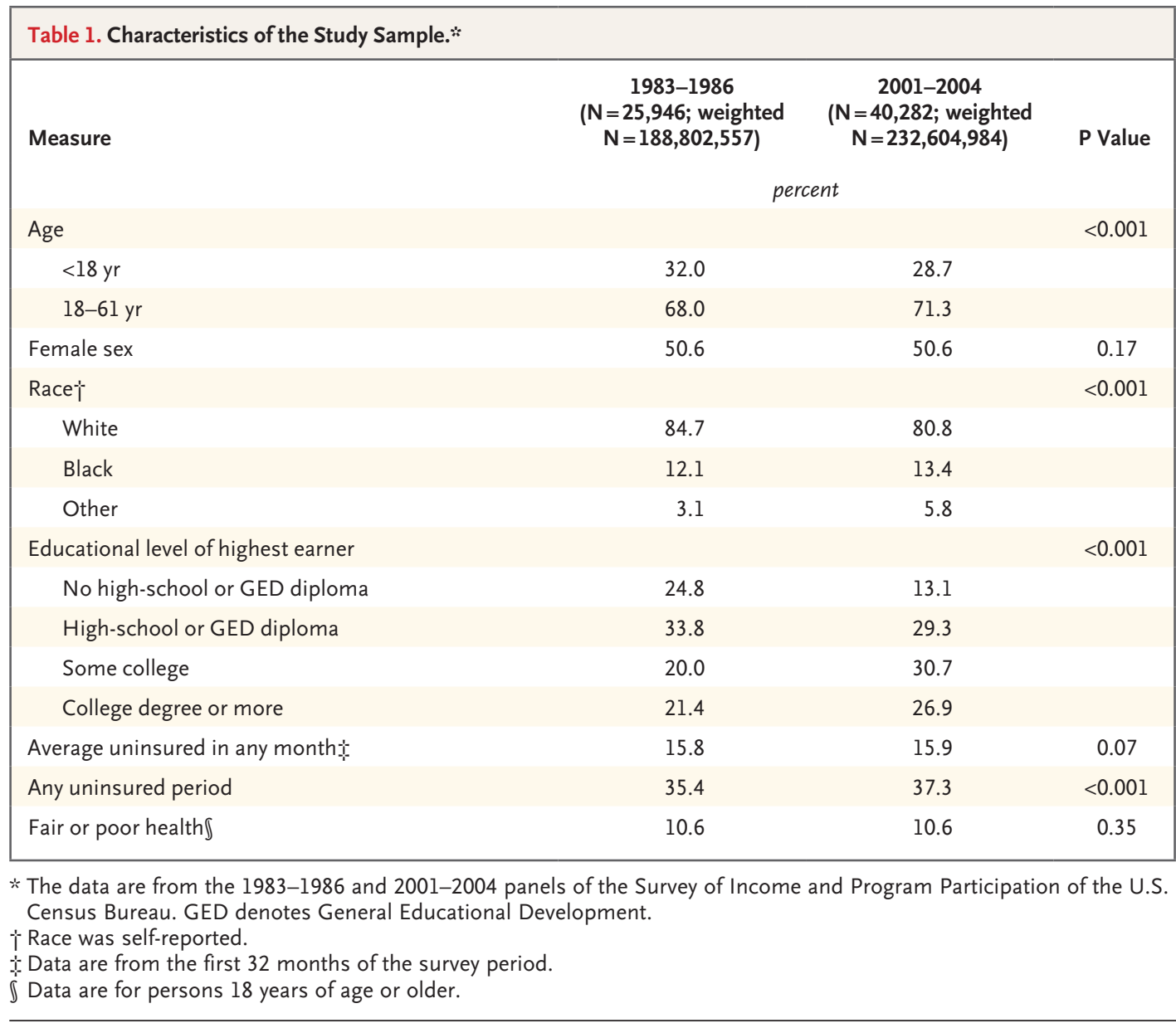

being uninsured are shown for each survey in Table 2. The coefficient estimates were in the expected direction in all cases. Whites and persons with a higher educational level generally had lower hazard rates for loss of coverage than persons of other races or ethnic groups and those with a lower educational level. When they obtained coverage after an uninsured period, younger persons, persons with a lower educational level, and nonwhites were more likely to obtain public coverage.

\section{PROBABILITY OF LOSING COVERAGE}

The predicted probability that an insured person would lose coverage at some time in the subsequent 12-month period, with the demographic mix of the population held constant, is shown in Table 3. The percentage of persons who lost coverage in a 12-month period increased from $19.8 \%$ in $1983-1986$ to $21.8 \%$ in $2001-2004(\mathrm{P}=0.04)$. The increase was particularly large among per- sons with a lower educational level — an increase of 8.3 percentage points among persons without a high-school or GED diploma $(\mathrm{P}<0.001)$, as compared with an increase of 0.3 percentage point among those with a college degree or more $(\mathrm{P}=0.47)$.

The percentage of persons who had had public coverage and who lost it was greater than the percentage of those who had had private coverage and lost it. However, because so many more people had private coverage than public coverage, persons with private insurance accounted for a greater share of uninsured periods than did those with public insurance: of the persons who lost coverage in 1983-1986, 78.4\% lost private coverage, and of the persons who lost coverage in 2001-2004, 63.3\% lost private coverage.

The composition of the group without a highschool or GED diploma has changed markedly over time. In the 1980s, this group had a large 


\begin{tabular}{|c|c|c|c|c|}
\hline \multirow[t]{2}{*}{ Variable } & \multicolumn{2}{|c|}{$\begin{array}{l}\text { Hazard Ratio for Losing } \\
\text { Insurance }(95 \% \mathrm{CI})\end{array}$} & \multicolumn{2}{|c|}{$\begin{array}{l}\text { Hazard Ratio for Gaining } \\
\text { Insurance }(95 \% \mathrm{CI})\end{array}$} \\
\hline & $\begin{array}{l}1983-1986 \\
(N=24,858)\end{array}$ & $\begin{array}{l}2001-2004 \\
(N=38,704)\end{array}$ & $\begin{array}{l}1983-1986 \\
(N=8,706)\end{array}$ & $\begin{array}{c}2001-2004 \\
(\mathrm{~N}=14,443)\end{array}$ \\
\hline \multicolumn{5}{|l|}{ Private coverage } \\
\hline \multicolumn{5}{|l|}{ Age } \\
\hline $18-61 \mathrm{yr}$ & 1.00 & 1.00 & 1.00 & 1.00 \\
\hline$<18 \mathrm{yr}$ & $1.02(0.97-1.08)$ & $1.03(0.98-1.08)$ & $0.98(0.94-1.02)$ & $1.20(1.16-1.24)$ \\
\hline \multicolumn{5}{|l|}{ Educational level of highest earner } \\
\hline No high-school or GED diploma & 1.00 & 1.00 & 1.00 & 1.00 \\
\hline High-school or GED diploma & $0.89(0.83-0.95)$ & $0.85(0.79-0.90)$ & $1.27(1.21-1.34)$ & $1.35(1.28-1.43)$ \\
\hline Some college & $0.90(0.83-0.97)$ & $0.74(0.69-0.79)$ & $1.42(1.34-1.50)$ & $1.59(1.51-1.67)$ \\
\hline College degree or more & $0.49(0.44-0.53)$ & $0.46(0.43-0.50)$ & $1.37(1.29-1.46)$ & $1.77(1.67-1.87)$ \\
\hline \multicolumn{5}{|l|}{ Sex } \\
\hline Male & 1.00 & 1.00 & 1.00 & 1.00 \\
\hline Female & $0.89(0.85-0.94)$ & $0.84(0.80-0.88)$ & $1.04(1.00-1.08)$ & $0.97(0.94-1.00)$ \\
\hline \multicolumn{5}{|l|}{ Race $\dagger$} \\
\hline White & 1.00 & 1.00 & 1.00 & 1.00 \\
\hline Black & $1.35(1.25-1.45)$ & $1.24(1.17-1.32)$ & 1.03 (0.97-1.09) & $1.01(0.97-1.06)$ \\
\hline Other & $1.24(1.08-1.43)$ & $1.34(1.23-1.46)$ & $0.95(0.85-1.06)$ & $0.98(0.92-1.05)$ \\
\hline \multicolumn{5}{|l|}{ Public coverage } \\
\hline \multicolumn{5}{|l|}{ Age } \\
\hline $18-61$ yr & 1.00 & 1.00 & 1.00 & 1.00 \\
\hline$<18 \mathrm{yr}$ & $2.29(1.97-2.65)$ & $2.34(2.16-2.54)$ & $2.19(1.90-2.51)$ & $2.26(2.11-2.41)$ \\
\hline \multicolumn{5}{|l|}{ Educational level of highest earner } \\
\hline No high-school or GED diploma & 1.00 & 1.00 & 1.00 & 1.00 \\
\hline High-school or GED diploma & $0.49(0.42-0.59)$ & $0.54(0.49-0.60)$ & $0.58(0.50-0.68)$ & $0.60(0.55-0.65)$ \\
\hline Some college & $0.29(0.23-0.36)$ & $0.34(0.31-0.39)$ & $0.32(0.26-0.40)$ & $0.38(0.34-0.42)$ \\
\hline College degree or more & $0.16(0.11-0.24)$ & $0.19(0.16-0.23)$ & $0.20(0.14-0.29)$ & $0.23(0.20-0.26)$ \\
\hline \multicolumn{5}{|l|}{ Sex } \\
\hline Male & 1.00 & 1.00 & 1.00 & 1.00 \\
\hline Female & $1.40(1.21-1.62)$ & $1.61(1.48-1.74)$ & $1.44(1.25-1.66)$ & $1.50(1.41-1.60)$ \\
\hline \multicolumn{5}{|l|}{ Race† } \\
\hline White & 1.00 & 1.00 & 1.00 & 1.00 \\
\hline Black & $1.53(1.28-1.83)$ & $1.45(1.31-1.60)$ & $1.65(1.40-1.94)$ & $1.41(1.30-1.52)$ \\
\hline Other & $1.01(0.66-1.52)$ & $1.47(1.26-1.71)$ & 1.37 (0.99-1.89) & $1.39(1.22-1.58)$ \\
\hline
\end{tabular}

* The data are from the 1983-1986 and 2001-2004 panels of the Survey of Income and Program Participation of the U.S. Census Bureau. GED denotes General Educational Development.

$\uparrow$ Race was self-reported.

component of older white men who had a history of employment in manufacturing industries and secure health insurance coverage. By the early 2000 s, the people in that group had largely retired and, because of our age criterion for eligi- bility, were no longer included in the sample; the group therefore comprised younger persons. Nevertheless, the greatly increased incidence of loss of insurance among persons with a lower educational level is not a consequence of demo- 
graphic change. When only persons 20 to 40 years of age were included in the analysis, the percentage of persons with less than 12 years of education who became uninsured over a 12-month interval increased from $24.2 \%$ in the 1980 s to $35.1 \%$ in the 2000s $(\mathrm{P}<0.001)$.

\section{REGAINING COVERAGE AFTER AN UNINSURED PERIOD}

Table 4 shows the distribution of the time spent without insurance, with the demographic mix of the population held constant. The percentage of persons who did not have any uninsured period over the course of 32 months decreased from $66.1 \%$ in $1983-1986$ to $62.5 \%$ in $2001-2004(\mathrm{P}<0.001)$. Table 4 also shows the duration of uninsured periods for those persons in both panels who were uninsured for any length of time. The percentage of the full population that obtained insurance coverage was higher in the 2001-2004 panel than in the 1983-1986 panel for every period shown in Table 4. In the 1983-1986 panel, $59.2 \%$ of those who were uninsured obtained insurance within 1 year, and $73.8 \%$ obtained insurance within 2 years; in the 2001-2004 panel, 61.7\% obtained insurance within 1 year, and $79.7 \%$ within 2 years $(\mathrm{P}<0.001$ for both comparisons with the 1983-1986 panel).

Figure 1 shows the changing rates of transition into private or public coverage. The probability that persons with an uninsured period would obtain private insurance within 24 months decreased by 6.0 percentage points from 1983-1986 (65.2\%) to $2001-2004$ (59.2\%) $(\mathrm{P}<0.001)$. There was an increase in the probability of obtaining public coverage, however, which more than offset the decline in private coverage. Twenty-four months after the uninsured period started, the percentage of the population that had transitioned to public coverage was 11.7 percentage points higher in the 2001-2004 panel than in the 1983-1986 panel.

An analysis according to demographic group showed that the percentage of persons who obtained private insurance within 24 months decreased among both children and adults, whereas the percentage of those who obtained public insurance increased among both groups (see the Supplementary Appendix, available with the full text of this article at NEJM.org). The percentage of persons who obtained private insurance within 24 months decreased by 12.0 percentage points

\begin{tabular}{|c|c|c|c|}
\hline Variable & $1983-1986$ & 2001-2004 & P Value \\
\hline & \multicolumn{2}{|c|}{$\%$} & \\
\hline Total sample & 19.8 & 21.8 & 0.04 \\
\hline \multicolumn{4}{|l|}{ Age } \\
\hline$<18 \mathrm{yr}$ & 21.8 & 25.5 & 0.02 \\
\hline $18-61 \mathrm{yr}$ & 18.8 & 20.2 & 0.14 \\
\hline \multicolumn{4}{|l|}{ Educational level of highest earner } \\
\hline No high-school or GED diploma & 32.0 & 40.3 & $<0.001$ \\
\hline High-school or GED diploma & 19.3 & 21.1 & 0.09 \\
\hline Some college & 18.5 & 17.8 & 0.25 \\
\hline College degree or more & 9.9 & 10.2 & 0.47 \\
\hline \multicolumn{4}{|l|}{ Previous coverage } \\
\hline Public & 37.7 & 41.9 & 0.04 \\
\hline Private & 13.6 & 12.2 & 0.12 \\
\hline \multicolumn{4}{|l|}{ Health status $†$} \\
\hline Fair or poor & 19.3 & 30.5 & $<0.001$ \\
\hline Good, very good, or excellent & 14.4 & 17.7 & 0.02 \\
\hline
\end{tabular}

* The data are from the 1983-1986 and 2001-2004 panels of the Survey of Income and Program Participation of the U.S. Census Bureau. Estimates were obtained for each demographic group and were weighted by the average population share of the demographic group over the two survey periods. GED denotes General Educational Development.

$\uparrow$ Results for health status are based on a sample of only persons who were 18 to 61 years of age and do not include data from the first 12 months of the survey period.

in households in which the highest earner did not have a high-school diploma. This decline was more than offset by an increase of 20.6 percentage points in public coverage in that group.

\section{INSURANCE COVERAGE AND HEALTH STATUS}

As shown in Table 3, the probability of losing coverage increased by 11.2 percentage points between the two survey periods among persons who reported that they were in fair or poor health $(\mathrm{P}<0.001)$, as compared with an increase of 3.3 percentage points among those who reported that they were in excellent, very good, or good health $(\mathrm{P}=0.02)$. In both groups, however, uninsured periods became shorter. As shown in Table 4, the percentage of persons in fair or poor health who obtained insurance within 12 months increased from $62.8 \%$ to $76.4 \%$ between the two survey periods, and the percentage of those in excellent, very good, or good health who obtained insurance within 12 months increased from 51.5\% to $63.8 \%$. The larger increase among those in worse 


\begin{tabular}{|c|c|c|c|c|c|}
\hline \multirow[t]{2}{*}{ Variable } & \multicolumn{5}{|c|}{ Duration of Uninsured Period } \\
\hline & 0 Months & 1-4 Months & $\begin{array}{c}\text { 5-12 Months } \\
\text { percent }\end{array}$ & 13-24 Months & $>24$ Months \\
\hline \multicolumn{6}{|l|}{ 1983-1986 } \\
\hline Total sample & 66.1 & 40.8 & 18.4 & 14.6 & 26.2 \\
\hline \multicolumn{6}{|l|}{ Age } \\
\hline$<18 \mathrm{yr}$ & 66.8 & 42.0 & 19.1 & 15.2 & 23.8 \\
\hline $18-61 \mathrm{yr}$ & 65.9 & 40.3 & 18.1 & 14.3 & 27.2 \\
\hline \multicolumn{6}{|l|}{ Educational level of highest earner } \\
\hline No high-school or GED diploma & 51.9 & 36.9 & 18.7 & 16.9 & 28.0 \\
\hline High-school or GED diploma & 36.5 & 41.0 & 18.6 & 14.8 & 25.7 \\
\hline Some college & 67.2 & 43.1 & 18.4 & 14.0 & 24.6 \\
\hline College degree or more & 80.2 & 41.2 & 18.0 & 13.8 & 27.0 \\
\hline \multicolumn{6}{|l|}{ Health status' } \\
\hline Fair or poor & 60.7 & 32.4 & 20.4 & NA & NA \\
\hline Good, very good, or excellent & 68.2 & 33.9 & 17.6 & NA & NA \\
\hline \multicolumn{6}{|l|}{ 2001-2004 } \\
\hline Total sample & $62.5 \div$ & $42.0 \div$ & 19.7 & $18.0 \div$ & $20.3 \ddagger$ \\
\hline \multicolumn{6}{|l|}{ Age } \\
\hline$<18 \mathrm{yr}$ & $64.5 \ddagger$ & $51.2 \div$ & $20.6 \%$ & 16.4 & $11.8 \div$ \\
\hline $18-61$ yr & $61.5 \div$ & $37.9 \div$ & 19.3 & $18.7 \dagger$ & $24.0 \div$ \\
\hline \multicolumn{6}{|l|}{ Educational level of highest earner } \\
\hline No high-school or GED diploma & $36.5 \div$ & $41.9 \div$ & $20.1 \%$ & $18.7 \div$ & $19.4 \div$ \\
\hline High-school or GED diploma & $34.2 \hbar$ & 41.1 & $19.7 \div$ & $18.3 \div$ & $20.8 \div$ \\
\hline Some college & 67.2 & $41.9 \div$ & $19.6 \div$ & $17.8 \div$ & $20.3 \div$ \\
\hline College degree or more & $82.0 \div$ & $43.2 \div$ & $19.5 \div$ & $17.4 \%$ & $20.0 \div$ \\
\hline \multicolumn{6}{|l|}{ Health status' } \\
\hline Fair or poor & 57.2 & $56.3 \div$ & 20.1 & NA & NA \\
\hline Good, very good, or excellent & 65.1 & $41.5 \div$ & $22.3 \div$ & NA & NA \\
\hline
\end{tabular}

* The data are from the 1983-1986 and 2001-2004 panels of the Survey of Income and Program Participation of the U.S. Census Bureau. Estimates were obtained for each demographic group and were weighted by the average population share of the demographic group over the two survey periods. GED denotes General Educational Development.

$\dagger$ Results for health status are based on a sample of only persons who were 18 to 61 years of age. Because they do not include data from the first 12 months of the survey period, some estimates were not available (NA).

$¥ \mathrm{P}<0.05$ for the change from the 1983-1986 period.

health resulted primarily from the fact that they were more likely than those in better health to obtain public insurance. Tables 2 and 3 in the Supplementary Appendix show hazard ratios with respect to health status.

\section{DISCUSSION}

Our analysis of uninsured periods suggests several conclusions. First, the incidence of uninsured periods is rising over time, especially among per- sons with a lower educational level. The majority of uninsured periods involve the loss of private insurance, but an increased chance of losing public coverage over time accounts for the increase in loss of insurance from the earlier survey period to the later period. Second, when people become uninsured, they are uninsured for shorter periods. The percentage of persons who were uninsured for 2 years or longer, for example, decreased from $26.2 \%$ to $20.3 \%$ between the two study periods. Third, uninsured periods are shorter because more 


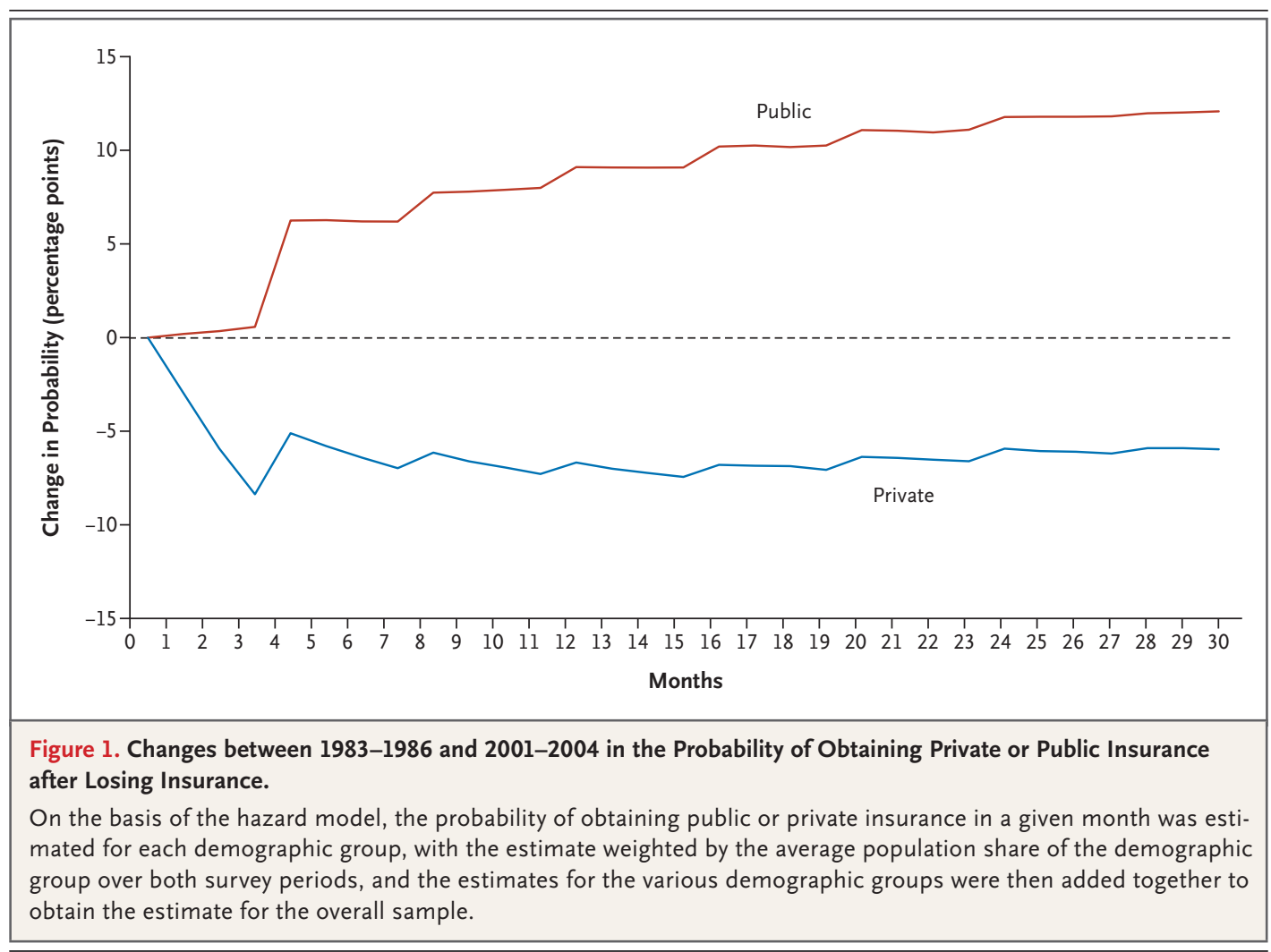

people are obtaining public insurance. From the mid-1980s to the early 2000s, the percentage of uninsured periods that ended in coverage with private insurance decreased by 6.0 percentage points, whereas the percentage that ended in coverage with public insurance increased by 11.7 percentage points. Fourth, in the 2001-2004 survey, persons who were in fair or poor health were substantially more likely than persons in good, very good, or excellent health both to lose and to gain insurance. This finding is a result of the increase in public insurance, which persons who are less healthy are more apt to have.

The increase in the percentage of the population that was uninsured in any month was smaller in our analysis than in other analyses of SIPP data, ${ }^{25}$ and it is smaller than the increase in the percentage of the population without coverage for an entire year that was shown in the Current Population Survey. ${ }^{26,27}$ This difference is largely a result of the sample weights. The longitudinal and cross-sectional weights in the 20012004 survey give somewhat different estimates of the percentage of persons who were uninsured in any month (see the Supplementary Appendix). Since the longitudinal weights are most appro- priate for the duration analysis, we presented results using these weights. The main results of the analysis were substantively unchanged when the cross-sectional weights were used.

The increased incidence of uninsured periods among persons with the lowest educational level as compared with those who were more educated parallels and reinforces the economy-wide increase in income inequality during this time. ${ }^{28}$ It may also reflect the fact that employers are charging employees increasing amounts for health insurance and that there is a trend toward increases in temporary and seasonal employment. ${ }^{9}$ We have performed the analysis using income ranges in place of educational levels, with similar results.

Many people become uninsured because they lose their job; however, changes in job duration do not explain our results. When we estimated our hazard models with adjustment for the employment status of a person and other members of his or her family, we found a decrease in the length of uninsured periods between 1983-1986 and 2001-2004 that was similar to the decrease in the model that did not control for employment status (data not shown). Similarly, we found that 
the increase between 1983-1986 and 2001-2004 in the probability of losing insurance was similar to the increase in the model that did not control for employment status.

The decrease in the duration of uninsured periods is not surprising, given the enormous increase in Medicaid coverage over time, particularly for children and parents with a lower educational level. ${ }^{29}$ It is possible that increased Medicaid coverage could also be partly responsible for the relatively large decrease in private coverage, if increased eligibility for public coverage led to an increased number of people who no longer had private coverage. Our results do not address this issue. ${ }^{30}$ We did find that many people, especially children and persons who were less healthy, cycled into and out of Medicaid.

Our study has some important limitations. First, the SIPP is subject to "seam bias" — that is, the tendency for people to report the same insurance status in blocks of 4 months. However, this bias should be the same in each survey. Second, different weights were used in the two surveys, an issue noted above. Third, our analysis focused only on the incidence and duration of periods of no insurance; we did not examine the health outcomes of persons who were uninsured. Finally, we looked at data for uninsured persons and did not analyze data for those who were underinsured.

In conclusion, uninsured periods are more prevalent, but shorter, now than they were two decades ago. A decline in private coverage, especially for persons with a lower educational level, has been offset by an increase in public coverage. Serious problems could lie ahead if employerbased coverage continues to decline while the availability of public coverage remains the same or is reduced.

Supported by grants from the National Institute on Aging (PO1AG005842, to Dr. Cutler, and T32AG000186, to Dr. Gelber).

No potential conflict of interest relevant to this article was reported.

\section{REFERENCES}

1. DeNavas-Walt C, Proctor BD, Smith JC. Income, poverty, and health insurance coverage in the United States: 2007. Washington, DC: Government Printing Office, 2008.

2. Swartz K. Dynamics of people without health insurance: don't let the numbers fool you. JAMA 1994;271:64-6.

3. Institute of Medicine, Committee on the Consequences of Uninsurance. Care without coverage: too little, too late. Washington, DC: National Academy Press, 2002. 4. Hadley J. Sicker and poorer - the consequences of being uninsured: a review of the research on the relationship between health insurance, medical care use, health, work, and income. Med Care Res Rev 2003;60:Suppl:3S-75S.

5. Ayanian JZ, Weissman JS, Schneider EC, Ginsburg JA, Zaslavsky AM. Unmet health needs of uninsured adults in the United States. JAMA 2000;284:2061-9.

6. Baker DW, Sudano JJ, Albert JM, Borawski EA, Dor A. Lack of health insurance and decline in overall health in late middle age. N Engl J Med 2001;345:110612.

7. Idem. Loss of health insurance and the risk for a decline in self-reported health and physical functioning. Med Care 2002; 40:1126-31.

8. Bodenheimer $T$. Insuring the uninsured: will the 2004 election provide an answer? Ann Intern Med 2004;141:556-61. 9. Farber HS, Levy H. Recent trends in employer-sponsored health insurance coverage: are bad jobs getting worse? J Health Econ 2000;19:93-119.
10. Chernew M, Cutler DM, Keenan PS. Increasing health insurance costs and the decline in insurance coverage. Health Serv Res 2005;40:1021-39.

11. Zuckerman S, Haley J. Variation and trends in the duration of uninsurance. Washington, DC: The Urban Institute, 2004.

12. Bureau of the Census. Health insurance coverage, 1992 to 1993: who loses coverage and for how long? Washington, DC: Government Printing Office, 1996.

13. Idem. Health insurance coverage, 1991 to 1993. Washington, DC: Government Printing Office, 1995.

14. Idem. Health insurance coverage, 1990 to 1992. Washington, DC: Government Printing Office, 1994.

15. Idem. Health insurance coverage, 1986 to 1988. Washington, DC: Government Printing Office, 1990.

16. Idem. Health insurance coverage, 1993 to 1995: who loses coverage and for how long? Washington, DC: Government Printing Office, 1998.

17. Survey of income and program participation (SIPP). Washington, DC: Census Bureau. (Accessed March 30, 2009, at http://www.sipp.census.gov/sipp/.)

18. Summers LH. Some simple economics of mandated benefits. Am Econ Rev 1989;79:177-83.

19. Gruber J. The incidence of mandated maternity benefits. Am Econ Rev 1994;84: 622-41.

20. Solon G. Intergenerational mobility in the labor market. In: Ashenfelter O, Card D, eds. Handbook of labor economics. Am- sterdam: Elsevier Science BV, 1999:1761800.

21. Haider S, Solon G. Life-cycle variation in the association between current and lifetime earnings. Am Econ Rev 2006;96: 1308-20.

22. Lunn M, McNeil D. Applying Cox regression to competing risks. Biometrics 1995;51:524-32.

23. Kalbfleisch JD, Prentice RL. The statistical analysis of failure time data. 2nd ed. Hoboken, NJ: John Wiley, 2002.

24. Stata, ed. 9.2. College Station, TX: Stata Corporation, 1996.

25. Bhandari S. People with health insurance: a comparison of estimates from two surveys. Washington, DC: Census Bureau, 2004.

26. General Accounting Office. Private health insurance: continued erosion of coverage linked to cost pressures. Washington, DC: Government Printing Office, 1997.

27. DeNavas-Walt C, Proctor BD, Lee CH. Income, poverty, and health insurance coverage in the United States: 2005. Washington, DC: Government Printing Office, 2006.

28. Autor DH, Katz LF, Kearney MS. The polarization of the U.S. labor market. Am Econ Rev 2006;96:189-94.

29. National Center for Health Statistics. Health, United States, 2006. Washington, DC: Government Printing Office, 2006.

30. Cutler DM, Gruber J. Does public insurance crowd out private insurance? Q J Econ 1996;11:391-430.

Copyright (c) 2009 Massachusetts Medical Society. 